\title{
Abstracts
}

\author{
Hans-Henrik Holm \\ Is the Third World Dead?
}

The end of the Third World has been proclaimed recently in many writings on the status and importance of the Third World in international relations. The failure to produce results in the so called North-South dialogue, and the tendencies towards differentiation within the Third World itself have been the premisses behind this conclusion. The conclusion is overdrawn. The Third World is an important actor in the present international system, and the fundamental problem is not lack of powerbase, but collective mobilization of these resources. Despite this the Third World is the exponent of one of the most central themes in the present international political debate, and will remain so.

\section{Georg Sørensen Democracy and Economic Development}

The transition towards more democratic forms of government in a number of Third World countries has fuelled the interest in democracy's consequences for economic development. The standard hypotheses claim that democracy promotes welfare, whereas authoritarian regimes perform better with respect to economic growth. A case-study of India shows that reality is more complicated. Democracy only provides welfare under certain preconditions, and authoritarian growthmanship also requires certain preconditions. Unfortunately, the analyses based on aggregated data from many countries are not well suited to capture this more nuanced picture. There are no easy solutions to the dilemmas of strengths and weaknesses of democratic and authoritarian regimes.

\section{Mette Skak \\ The Interventions of the Superpowers in the Third World}

The article demonstrates how the United States and the Soviet Union have developed a policy of intervention in connection with crises and conflicts in the developing countries (LDCs). The U.S. has a longer tradition for LDC intervention than the Soviet Union, and economic interventions play a greater role for the U.S. than for the U.S.S.R. Apart from that there are obvious similarities in behaviour, accompanying doctrines and motives (e.g. establishing spheres of influence). In addition to the stated motives, some theoretical perspectives of the superpowers' interventions in extraregional conflicts are outlined. The causal models of explanation consider conflicts of interests to be the immediate cause of interventions and the development problems to be the underlying causes, and neither these nor the supplementary explanatory models justify the assumption that military interventions will cease as a matter of course. For that reason the current more thoughtful phase of the superpowers' intervention policy should be used to develop alternatives - in cooperation with the superpowers. 